\title{
A TRADUÇÃO QUADRINHÍSTICA: SINAIS DE CONFLITO ENTRE IMAGEM E TEXTO
}

\author{
Gisele Marion Rosa ${ }^{1}$
}

RESUMO: Apresentamos, aqui, uma breve discussão acerca dos sinais de conflito entre imagem e texto presentes em uma tradução de história em quadrinhos. A mensagem é veiculada em uma linguagem específica envolvendo dois códigos, verbal e visual, que delimita as opções do tradutor, como por exemplo a aplicação de uma tendência tradutória. Dessa forma, buscou-se verificar o tratamento usado nas tentativas de resgate do significado da mensagem pertencente a um contexto peculiar de uma cultura periférica (língua portuguesa, Brasil) num espaço de recepção cultural divergente e hegemônico (língua inglesa, EUA), tendo por base a hipótese de Venuti nos termos da qual a referida direção tradutória teria como resultado um texto "domesticado" na cultura anglo-saxônica e, portanto, claramente distanciado do texto original. Para tanto, o córpus de análise constitui-se de três histórias em quadrinhos da Turma da Mônica, com original e tradução veiculados na Internet, cujo personagem central é um digno representante dos costumes e do falar regional brasileiro, Chico Bento.

PALAVRAS-CHAVE: Estudos da tradução; História em quadrinhos; Marcadores culturais; Modalidades de tradução; Tradução domesticadora.

1 Mestranda pelo Programa de Pós-graduação em Semiótica e Linguística Geral na Universidade de São Paulo sob orientação do Prof ${ }^{\circ}$. Dr. Francis Henrik Aubert.

TradTerm, 16, 2010, p. 411-434 
ABSTRACT: A brief reflection upon the conflict signs between image and text within comic books translation. The message is grasped in a very peculiar way which involves two language codes, verbal and visual, that promote limits regarding the translator's choices. Therefore, the analysis focus on the context involving the specific translation direction from the periphery - Portuguese/BR - to the hegemonic language - English/USA - and how the message was produced in the translated text under the light of Venuti's translation theory of domesticating. The corpus is composed of three comic book stories by Mauricio de Sousa with original and translation obtained in the Internet website www.monica.com.br/index.htm

KEYWORDS: Translation studies; Comic books; Cultural markers; Translation modalities; Domesticating translation.

\section{Introdução}

Apoiando-se na exposição de Venuti (1995) sobre a tendência tradutória que objetiva o apagamento da alteridade cultural em favor de uma apropriação dos conceitos da cultura de origem pela cultura hegemônica, isto é, a tradução domesticadora, buscaremos discutir alguns pontos relevantes como por exemplo, a sua relação com a amarração imagética em uma história em quadrinhos discutidos primeiramente em nossa pesquisa de Iniciação Científica ${ }^{2}$. Os resultados alcançados partiram, principalmente, dos sinais de conflito encontrados em uma tradução quadrinhística detectados durante análise do nosso córpus principal, isto é, original e tradução veiculadas na Internet de três histórias em quadrinhos ${ }^{3}$ do personagem Chico Bento, da coleção Turma da Mônica.

2 Referimo-nos à pesquisa de Iniciação Científica que contou com apoio da FAPESP e que se intitula "Desafios da tradução cultural observados no universo do Chico Bento” (2007), orientação de Francis Henrik Aubert.

3 "O unicórnio"/"The Unicorn"; "Que furada de reportagem"/"Making News" e "Ou acabamos com as formigas..." /"Its' either us or the cutter

TradTerm, 16, 2010, p. 411-434 
A elaboração do projeto e posterior pesquisa consistiu em uma hipótese amparada pela análise da tradução de histórias em quadrinhos do Chico Bento veiculadas exclusivamente pela Internet ${ }^{4}$. Por conter elementos que expressam sua cultura de origem, destacados como marcadores culturais (Aubert:2006), despertou-se-nos o interesse em conferir, no confronto com o original, como esses elementos estão sendo transmitidos numa cultura divergente, tendo em conta, inter alia, as peculiaridades do próprio discurso quadrinhístico.

Após a análise contínua do córpus selecionado foi possível identificar uma forte tendência do tradutor ao processo assimilativo, em concordância com a descrição histórica de tradução de Venuti. Procurou-se eliminar o exotismo presente no texto de partida, dentro das limitações imagéticas, com o objetivo de universalizar os temas presentes na história, criando assim, uma identificação maior com o público alvo: infanto-juvenil pertencente à cultura Anglo-Americana. No entanto, notamos que a linguagem quadrinhística ofereceu um impasse favorável no que diz respeito à tendência em eliminar as marcas culturais provenientes do texto de origem.

É a partir dessa reflexão, justamente, que buscaremos discutir a característica intrínseca dessa linguagem que resulta na delimitação das escolhas do tradutor. Se, por um lado, notamos a possibilidade de identificar uma liberdade da própria imagem para uma tradução mais livre do original, tal como ilustraremos a seguir, por outro lado, essa liberdade demonstrou-se tolhida em alguns casos, resultando, inclusive, numa mudança imagética do texto de partida para o de chegada, caracterizando esse processo como uma adequação à tradução domesticadora.

ants" (cf. http://www.monica.com.br/index.htm). Para o presente artigo, optamos apenas pela análise da última HQ.].

4 Infelizmente, na época da pesquisa, não foi possível o acesso às traduções para o inglês de revistas em quadrinhos impressas da Turma da Mônica, somente as histórias veiculadas pela Internet.

TradTerm, 16, 2010, p. 411-434 


\section{A construção de sentido entre imagem e texto na HQ}

A $H Q$, ainda que identificada pela imagem, invariavelmente vem acompanhada do texto, dos elementos lingüisticos, que se fundem com a imagem e forma o código narrativo quadrinizado" (Cagnin, 1975: 119)

Essa afirmação de Cagnin introduz o conceito fundamental de que a linguagem quadrinhística é singular e articulada, exigindo uma leitura de seus componentes sígnicos, isto é, dos "signos e as relações entre signos em referência a um dado código" (Eco, 2004:131) que ambos, autor e leitor, devem compartilhar.

De fato, como nos alerta Moacy Cirne (1972), a linguagem dos quadrinhos é complexa e composta de mecanismos comunicacionais que expressam a sua narratividade semiologicamente através de imagens. Há um discurso narrativo dentro de uma expressão estética diferente, na qual existem planos de enquadramento, tal como no cinema, porém, realizando-se num continuum a partir de imagens estáticas. É a partir dessa sequência de imagens que se desenvolve o discurso narrativo.

Dessa forma, vemos que existe um processo composto de elementos variados resultando no produto da história em quadrinhos. Descreveremos, assim, como esse processo funciona e quais são seus elementos constitutivos, partindo da relação fundamental entre palavra e imagem.

Começando pela imagem, Cirne cita Barthes em sua definição de imagem como "um estado polissêmico voltado para o campo da representação, cuja estrutura significacional remeternos-ia a uma interrogação sobre o sentido" (Cirne, 1972:28). Para Cirne, a imagem, mais do que uma representação, é uma representificação, isto é, "a concretude dos signos que a compõe" (op. cit).

Veja-se, por exemplo, esta tira de Chico Bento: 


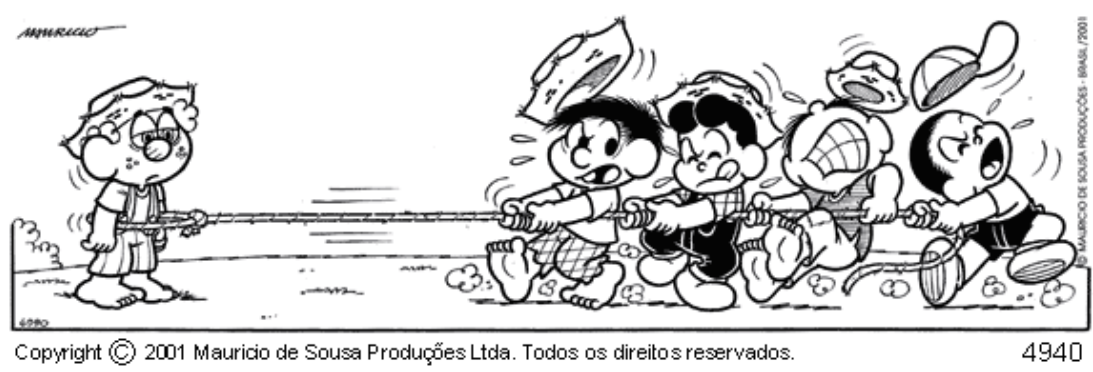

Figura 1: Tira 241 extraída de http://www.turmadamonica.com.br/ index.htm

Temos aqui, representada num quadrinho, apenas uma imagem sem texto verbal e, no entanto, recheada de significados. Pela leitura da imagem, vemos que o personagem Zé Lelé está em uma ponta do cabo de força, uma brincadeira infantil, ao passo que os demais garotos posicionam-se na outra ponta. São quatro meninos contra apenas um, e ainda assim, somente pela imagem podemos identificar que os quatro, embora estejam fazendo muita força com a corda, enquanto o Zé Lelé nenhuma, não conseguem movê-lo, para, assim, ganharem a brincadeira. A explicação para esse 'fenômeno' é que se trata exatamente da piada da tirinha, isto é, por conhecimento da cultura regional representada nessa imagem, sabemos que as mulas ou burros, quando 'empacam', nada os tira do lugar. Dessa forma, revelase para o leitor que o personagem Zé Lelé não se mexerá, ainda que motivado por quatro garotos ao mesmo tempo. Ou seja, há uma atribuição de burro (conotação de 'não inteligente') ao personagem na construção de sentido, que se dá pela leitura da imagem no quadrinho.

Desse modo, a imagem na história em quadrinhos, como elemento figurativo e com "implicações verbais e não verbais" (Cirne, 1972:35), objetiva transmitir uma mensagem que será decodificada pelo leitor, pois de acordo com Cagnin, ela é composta de elementos internos e externos (Cagnin, 1975:51) que possibilitam essa decodificação. Os elementos internos referemse à natureza da composição da imagem, ou seja, o traço, pontos, figuras etc; ao passo que os elementos externos fazem parte do universo do leitor, isto é, o referente dessa imagem, tais como, objetos, cultura e meio social. 
Outro fator interessante da imagem nos quadrinhos é seu caráter estático. Cirne evoca as palavras de outro importante teórico, Fresnault-Deruelle (1972:40), para refletir sobre esse aspecto, no qual "duas imagens já se organizam em narrativa", pois a leitura das imagens se dá numa "sucessão de quadros significantes". Cirne acredita na existência de uma "totalidade significacional, cujos parâmetros significantes estruturam visualmente a narrativa" (op. cit.). Desse modo, as imagens em cada quadrinho inter-relacionam-se para que a sua mensagem seja composta de significado.

Iniciemos, agora, a análise da função da palavra no contexto dos quadrinhos a partir da transição da função da imagem. Antes, contudo, precisamos refletir sobre outro aspecto fundamental que conecta esses dois códigos linguísticos, a iconografia. Eco (2004:144) dá uma especial atenção aos elementos iconográficos da HQ, pois acredita que esse gênero possui instrumentos gráficos próprios, caracterizando-os como "elementos figurativos, canônicos, com estatuto iconológico". Alguns exemplos que Eco apresenta em seu artigo são "ver estrelas, ter o coração em festa, sentir a cabeça rodar, roncar como uma serra" (2004:144), entre muitos outros, já que cada um deles é representado por um ícone correspondente e de significação compartilhada pelos criadores da HQ e leitores; por exemplo, 'ter uma ideia' fatalmente será representado por uma 'lâmpada acesa'.

Vemos, assim, que existe um "repertório simbólico" que Eco classifica como a "semântica da HQ", destacando como elemento fundamental dessa semântica o próprio balão de fala. $\mathrm{O}$ balão, além de transportar o texto da fala do personagem, é, primeiramente, uma imagem que constitui o desenho do quadrinho. Eco classifica o balão como "elemento de metalinguagem" (2004:145), pois, sendo um desenho, sua função imagética precisa corresponder à significação do discurso que transporta. Por exemplo, se o balão apresenta-se desenhado com traço reto em direção ao personagem, o leitor identificará que o discurso é expresso, falado. Nos casos em que o balão é unido à boca do personagem por bolinhas, o leitor imediatamente assume que o discurso é pensado.

O mesmo ocorre com o formato do texto, pois dentro desse repertório simbólico, sabemos que o discurso distingue-se a 
partir do formato do mesmo. Por exemplo, se o texto estiver anormalmente grande e em negrito, o personagem estará gritando; ocorre o mesmo no inverso: quando as letras são menores que o normal, o personagem estará sussurrando. O último exemplo também pode ser substituído pelo formato do balão, nos casos em que este for tracejado em vez de apresentar um traço reto.

Por fim, no campo da inter-relação palavra e imagem nos quadrinhos, podemos nos amparar no conceito de Barthes, pela interpretação de Cagnin (1975:120), quando afirma que a linguagem pode se unir à imagem, alternando com ela funções de dominância e complementaridade.

No universo quadrinhístico, destacamos duas funções básicas que Barthes (1975) atribui a essa linguagem: a fixação e a ligação. Na fixação, a palavra revela o sentido denotativo da imagem, ajudando na interpretação dos seus semas conotativos; a palavra, na verdade, seleciona o significado decodificando-o. Isso ocorre devido "à cadeia flutuante de significados" da qual uma imagem é constituída, necessitando da mensagem linguística para "dirigir a leitura segundo a intenção que o emissor lhe quer dar". Já na ligação, ambas, palavra e imagem, encontram-se em relação complementar, de caráter narrativo, pois enquanto a palavra transmite maior carga informativa, a imagem se incumbe das informações descritivas, tais como cenários e movimentos, por exemplo. No entanto, o autor também atenta para o fato de que, no momento em que a palavra está sendo confinada no balão de fala, esta passa a exercer a mesma função da imagem: em vez de narrar, ela representa.

Concluímos que a palavra convive com a imagem numa relação interdependente, existindo uma "junção dos dois sistemas, o icônico e o linguístico, em que nem sempre há fusão de igualdade de funções, mas a predominância de um sobre o outro (...)" (Cagnin, 1975:140). Em outras palavras, os efeitos de sentido são construídos no "sincretismo do verbal com o visual" (Discini, 2004:276), e é partindo dessa relação que se configura a (de)codificação do significado nas histórias em quadrinhos. 


\section{As marcas culturais versus a imagem no contexto tradutório}

No córpus analisado, vemos que o universo do Chico Bento apresenta marcas culturais reveladoras de sua cultura de origem, sendo compostas de significado na sua conjunção com a imagem do desenho. De fato, na tradução de histórias em quadrinhos, sendo o texto parte da própria imagem, faz-se necessário que outros fatores sejam levados em consideração na leitura e apreensão de significado pelo tradutor, tais como forma e tamanho dos balões, que trazem significados próprios, como vimos anteriormente.

É precisamente nessa relação, texto e imagem, que se situa a peculiaridade da tradução de história em quadrinhos. Essa amarração interdependente pode apresentar dificuldades e resistência na escolha de uma tendência tradutória que busca a invisibilidade do tradutor, pois o apagamento das marcas culturais, em muitos casos, pode contradizer a própria imagem do quadrinho.

Vejamos a seguir, com base nos resultados por amostragem obtidos do córpus selecionado para este artigo, a relação possivel de apoio da imagem para os casos em que a estratégia tradutória assimilativa se faz presente no resultado da análise. Em seguida, será possivel observar a relação truncada e conflituosa que demanda, inclusive, uma alteração imagética, como também outros recursos tradutórios. Os quadrinhos encontramse dispostos em paralelo português/inglês:

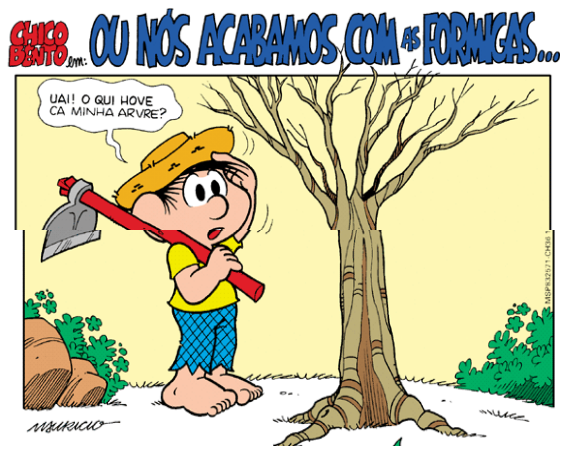

Figura 2:

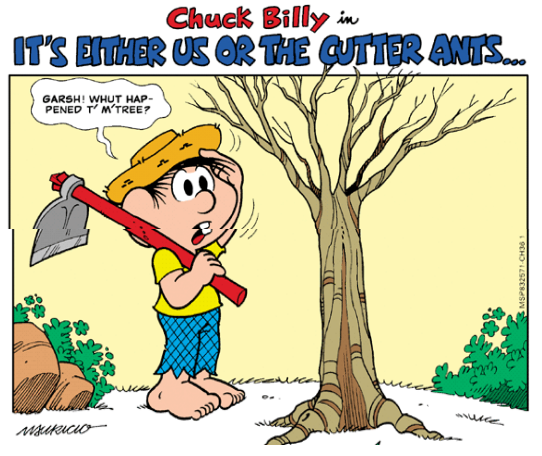

Figura 3:

TradTerm, 16, 2010, p. 411-434 
Na Figura 2, vemos que o título da história ${ }^{5}$ de Chico Bento - Ou nós acabamos com as formigas... - é uma referência ao slogan "Ou o Brasil acaba com a saúva ou a saúva acaba com o Brasil", que se tornou popular no governo da Era Vargas (193045). Interpretamo-la pela estrutura da frase e pela formiga em questão, pois se trata realmente de saúvas. Apesar de não ser possível confirmar com exatidão o seu autor original, há indícios de que o primeiro a citar essa frase publicamente foi o botânico francês Augustin Saint-Hilaire $(1799 / 1853)^{6}$ que, ao visitar o Brasil (1816-22), constatou que a saúva era uma praga agrícola.

O título, assim, carrega um forte semantismo na cultura/ língua de origem, renovado em seu uso desde então, pois a saúva tornou-se uma metáfora para as ditas 'pragas' que assolam o país, por exemplo, a corrupção ${ }^{7}$. Vemos que não há resgate do significado de origem na escolha do tradutor, ainda que este tenha optado por um equivalente popularmente conhecido na língua meta - "it's either us or...".

Podemos ver que a imagem do $1^{\circ}$ quadrinho não interfere nessa tradução, pois a mensagem da totalidade é naturalmente resgatada.

Vejamos, no nosso próximo exemplo, uma situação semelhante:

\footnotetext{
"Ou nós acabamos com as formigas..."/ "It's either us or the cutter ants...". http: / / pt.wikipedia.org.

"Ou o Brasil acaba com a saúva ou a saúva acaba com o Brasil" é um bordão utilizado metaforicamente por jornalistas e escritores em variados meios de comunicação nas situações caracterizadas por um problema social com natureza preocupante nacionalmente. Como podemos ver, também em Macunaíma de 1928 do célebre Mário de Andrade ("Pouca saúde e muita saúva, os males do Brasil são.") ou em Monteiro Lobato com o personagem Jeca Tatu (1924). Ao longo dos anos se utiliza muito esse bordão substituindo a saúva por problemas como a corrupção, ladroagem etc.

Cf.: http://www.antropologia.com.br/ (Entrevista com Gilberto Hochman - Edição $n^{\circ}$ 27); http://clipping.planejamento.gov.br/ (Artigo de Antônio Ermírio de Morais "Da saúva à corrupção"); http://www.cnoticias. com.br/
}

TradTerm, 16, 2010, p. 411-434 


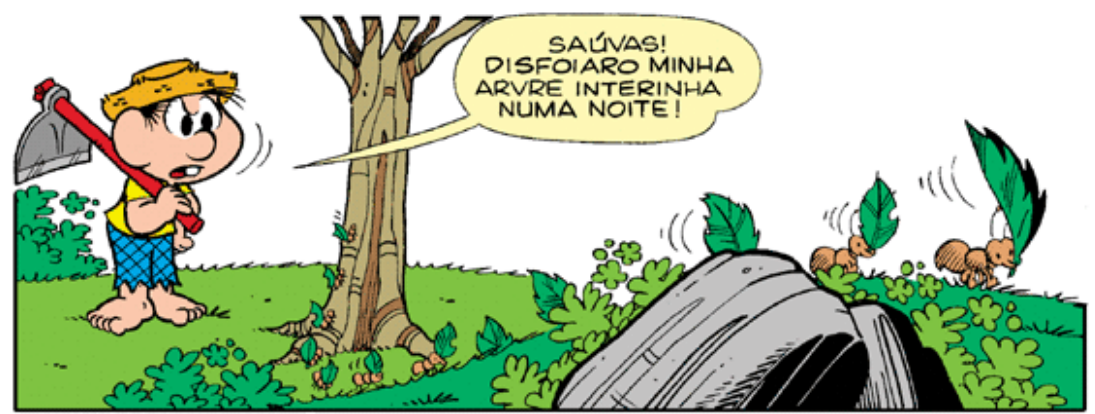

Copyright (C) 2002 Mauricio de Sousa Produçóes Ltda. Todos os direitos reservados.

Figura 4:

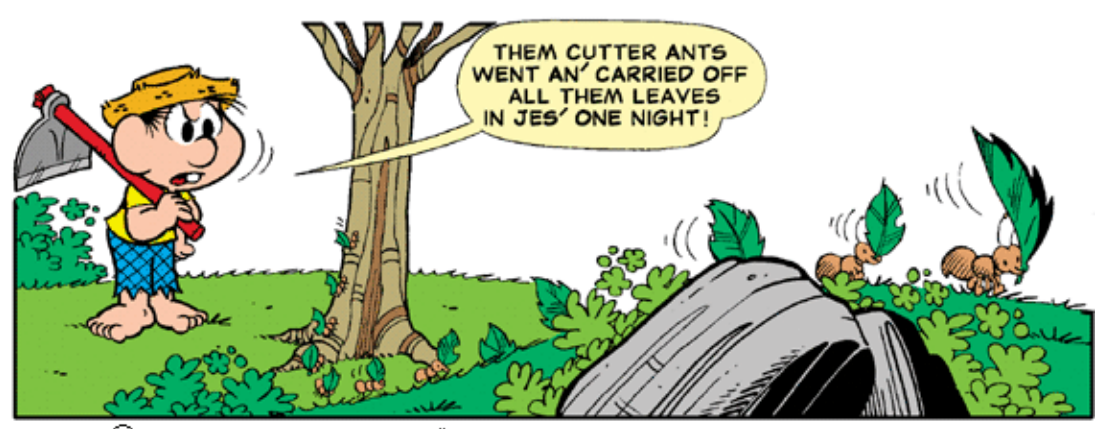

Copyright (C) 2002 Mauricio de Sousa Produộes Ltda. Redistribution in whole or in part prohibited.

Figura 5:

Como podemos ver, a tradução do termo da cultura ecológica (Mounin, 1975), "saúva", é "them cutter ants". O inseto mencionado no quadrinho é vastamente conhecido na cultura de origem, cujo jargão utilizado na área de biologia, formigas cortadeiras, tem o seu equivalente em inglês: "leaf-cutter ant" (Atta cephalotes). A modulação se dá pela escolha de "cutter ant", que parece adequar-se melhor ao discurso do personagem, além da inclusão do pronome "them", marca de coloquialidade regional, visto que saúva também é um termo popular.

Nas próximas sequências, veremos que a imagem, novamente, apoia e possibilita a modulação (Aubert, 1998) - a modalidade de tradução que elimina duas marcas culturais: "ôio do frumiguero" e "boca do frumiguero", características do regionalismo da lingua fonte:

TradTerm, 16, 2010, p. 411-434 

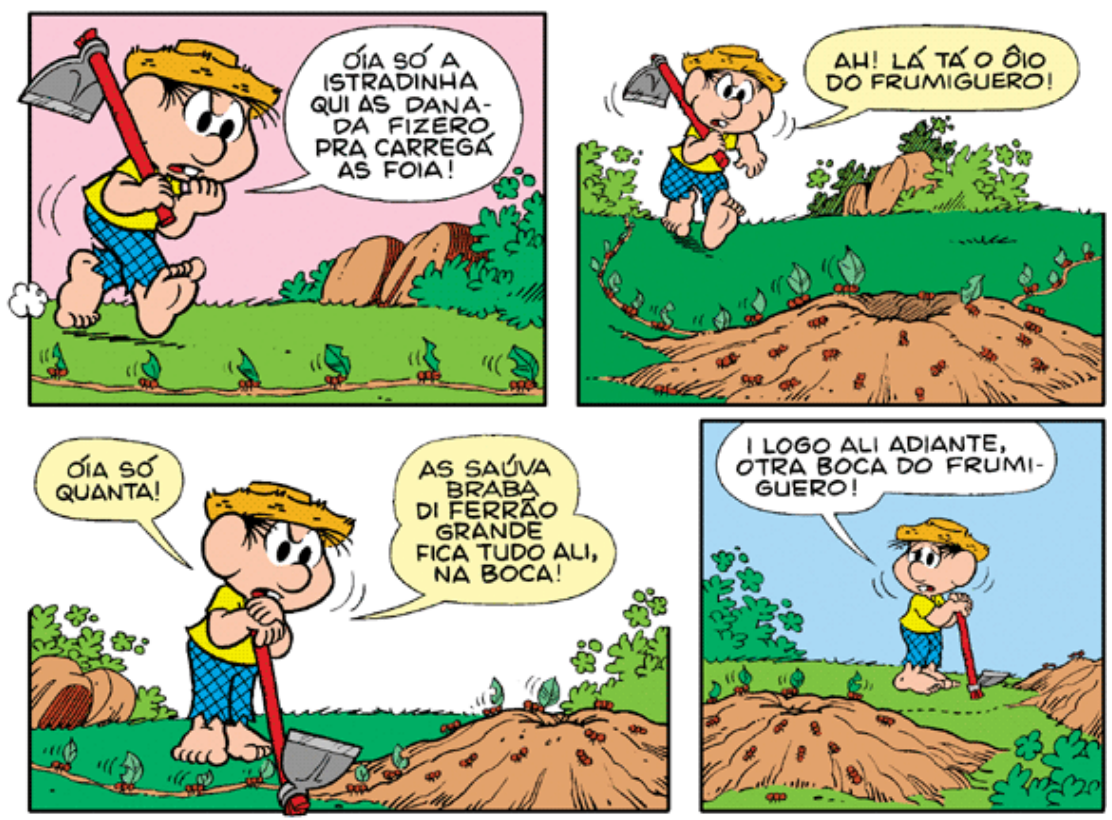

Figura 6:
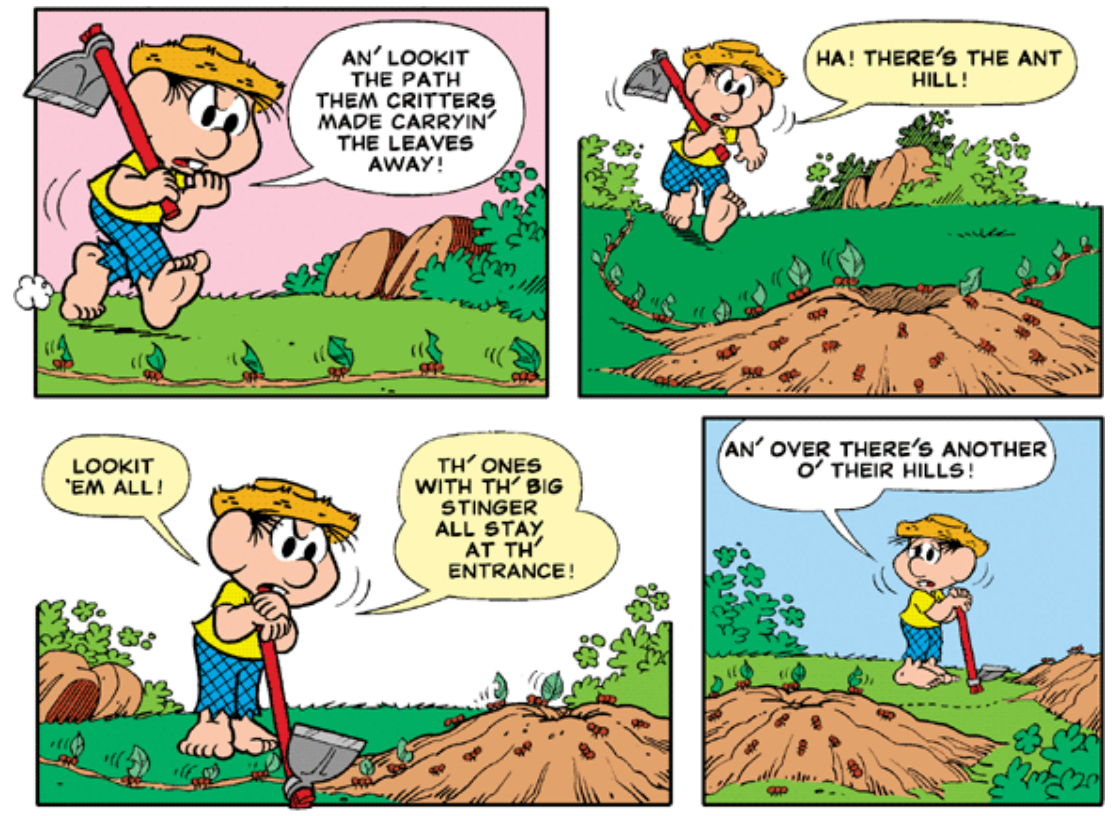

Figura 7:

TradTerm, 16, 2010, p. 411-434 
Na figura 6 ( $2^{\circ}$ quadro) ocorre aquilo que destacamos em nosso córpus como um marcador cultural: "ôio do frumiguero", que foi traduzido para ant hill. A ideia do objeto (formigueiro/ant hill) foi preservada; entretanto, há uma perda na especificidade do foco do personagem, pois até mesmo o plano da imagem, $1^{\circ}$ plano, apoia a fala do Chico.Esse diagnóstico, contudo, não desfaz a apreensão de sentido que a opção tradutória promove, pois o formigueiro, efetivamente, está lá.

$\mathrm{Na}$ análise da relação entre as Figuras 6 e 7, vemos também que no terceiro quadrinho de cada série o termo "entrance" aparece como o equivalente ao "boca", porém não é o mais apropriado. Apesar de, na língua meta, essa parte do formigueiro poder ser referida dessa forma, o termo popularmente conhecido seria mouth. Dessa maneira, além de adequado ao discurso do Chico Bento, o termo mouth passaria à tradução literal, caracterizando uma tendência de opacidade em vez de transparência da tradução.

Vejamos, agora, os casos de resistência promovida pela amarração imagética, que proporciona uma limitação no trabalho do tradutor no sentido de impulsioná-lo a uma tendência domesticadora. Os quadrinhos a seguir referem-se agora à outra história ${ }^{8}$ selecionada para o corpus da pesquisa.
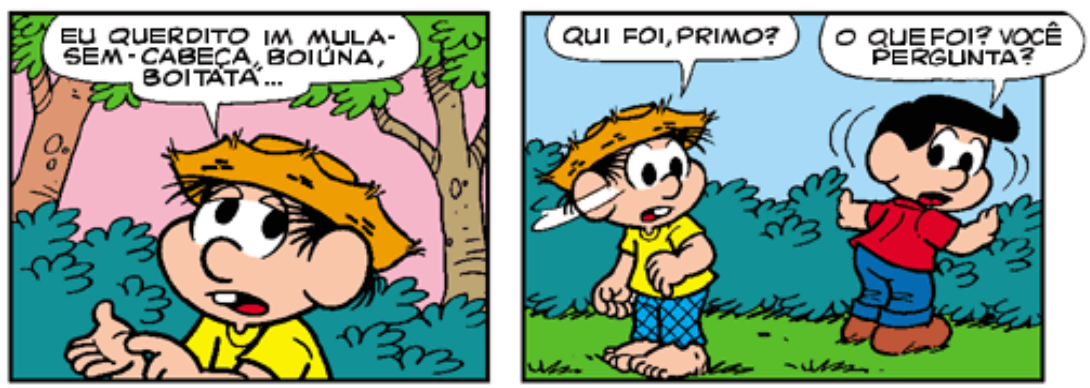

Copyright (C) 2001 Mauricio de Sousa Produộ́es Ltda. Todos os direitos reservados.

Figura 8:

8 "O unicórnio"/ "The Unicorn".

TradTerm, 16, 2010, p. 411-434 

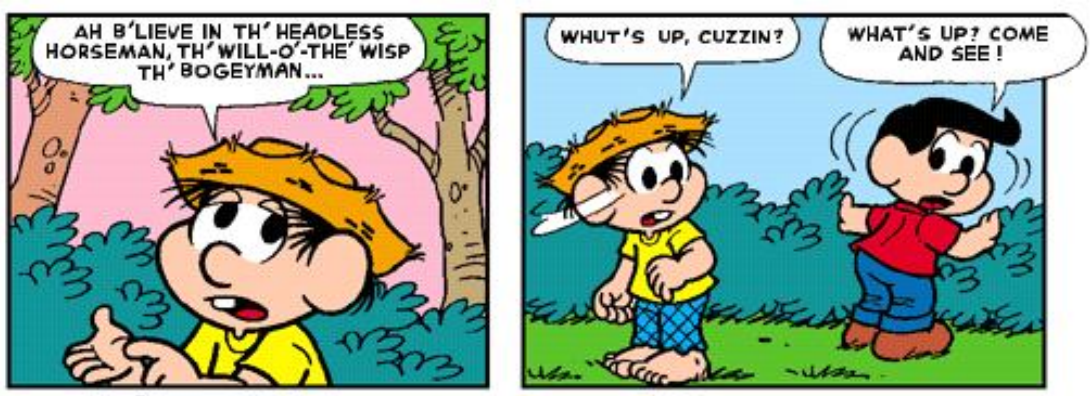

Copyright (C) 2001 Mauricio de Sousa Produộes Ltda. Redistribution in whole or in part prohibited.

Figura 9:

Nesse exemplo, vemos que o tradutor parece ter escolhido três figuras folclóricas da cultura anglo-Americana: headless horseman, will-o'-the'wisp e bogeyman, em paralelo às figuras da língua fonte (mula sem cabeça, boiúna, boitatá). Elas mantêm seu apelo popular ainda nos dias de hoje e, embora não sejam equivalentes, trazem características similares com as figuras da língua fonte. Por exemplo, temos a ausência da cabeça, no primeiro caso a do animal (LF), e no segundo, a do cavaleiro (LM), resgatando o efeito aterrorizante dos personagens.

No caso da boiúna e do boitatá, temos duas figuras que já compartilham semelhantes atributos entre si, tais como a capacidade de atrair o homem com uma luz sedutora com a intenção de desorientá-lo. Embora as informações sobre suas formas e comportamento tenham se transformado ao longo do tempo, acredita-se que o boitatá seja uma cobra de fogo que protege a floresta; quanto à boiúna, também conhecida como Mãe d'água, seria uma cobra grande ou sereia iluminada, que vaga pelos rios encantando os caboclos desavisados. No caso do seu correspondente na tradução, temos o "Will-o'-the'wisp", também conhecido como "Jack with a lantern". Aqui, a lenda conta que na Europa rural antiga, especialmente nas ilhas britânicas, uma luz tremeluzente (fogo fátuo) no meio da escuridão das estradas atrairia os viajantes para desviá-los do caminho.

A escolha do tradutor, até aqui, demonstrou especial interesse nas peculiaridades desses personagens. Por fim, para a terceira figura popular, vemos que o tradutor escolheu bogeyman. $\mathrm{O}$ interessante é que este apresenta o seu equivalente em portu- 
guês como sendo o "bicho-papão", já que ambos referem-se ao medo infantil de que um 'monstro' esconder-se-ia em seu quarto para atacar no escuro. Como vemos, esse caso é uma ocorrência de adaptação, isto é, totalmente livre do original.

Agora, vejamos o próximo exemplo para, em seguida, traçar as reflexões necessárias:
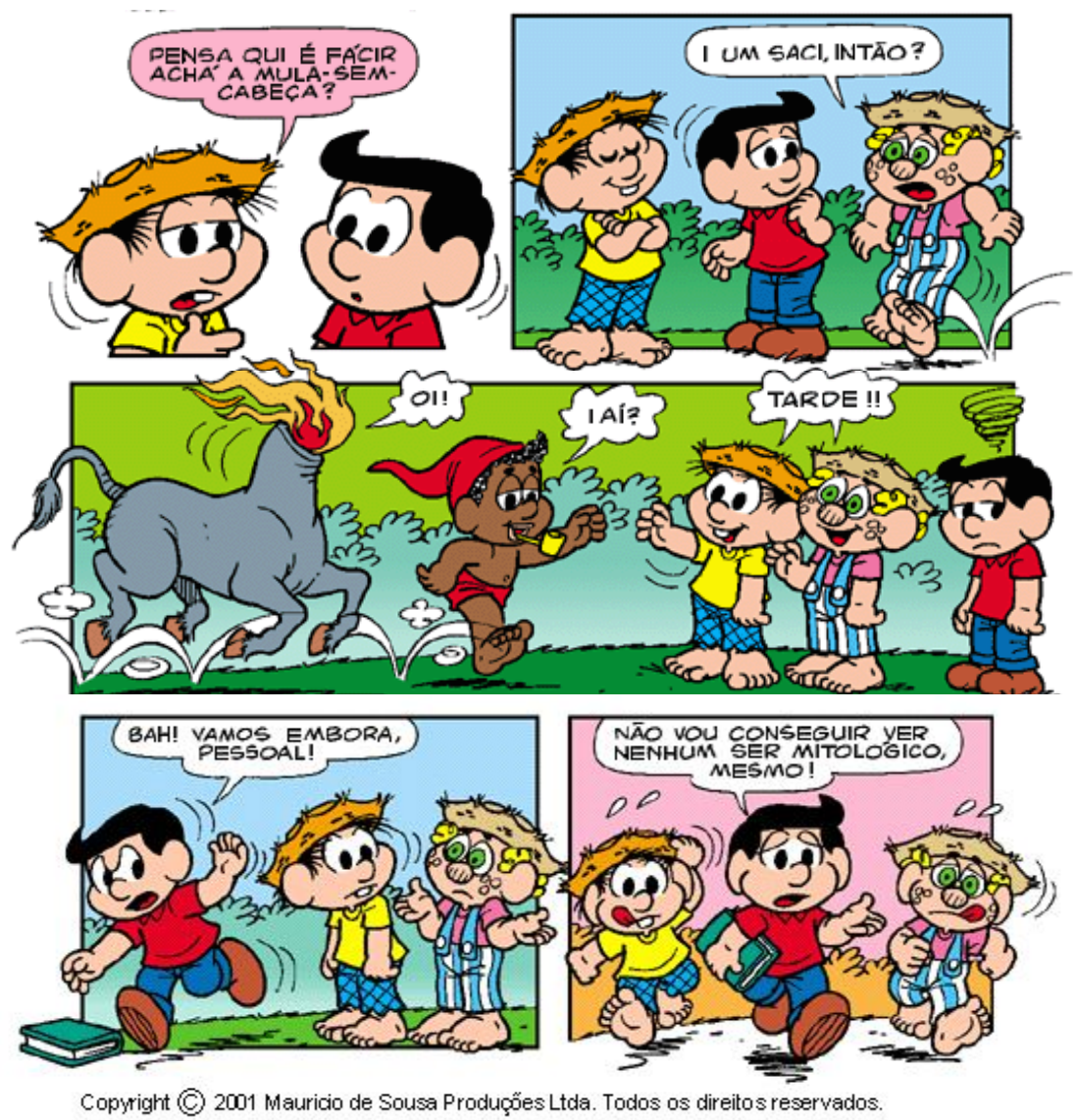

Figura 10:

Nessa sequência de quadrinhos, notamos que, novamente, há a presença do termo mula sem cabeça ( $1^{\circ}$ quadro), mas nesse momento, devido à sua ilustração efetivamente presente ( $3^{\circ}$ quadro), limitaram-se as opções do tradutor a desprezar a

TradTerm, 16, 2010, p. 411-434 
marca cultural brasileira. Notamos, na tradução correspondente a seguir, que o tradutor acabou criando um equivalente, uma tradução literal, que partiu da descrição do desenho no quadrinho. Nesse caso, o seu termo, headless mule, acabou sendo uma criação a partir da característica física da figura folclórica, senão vejamos:
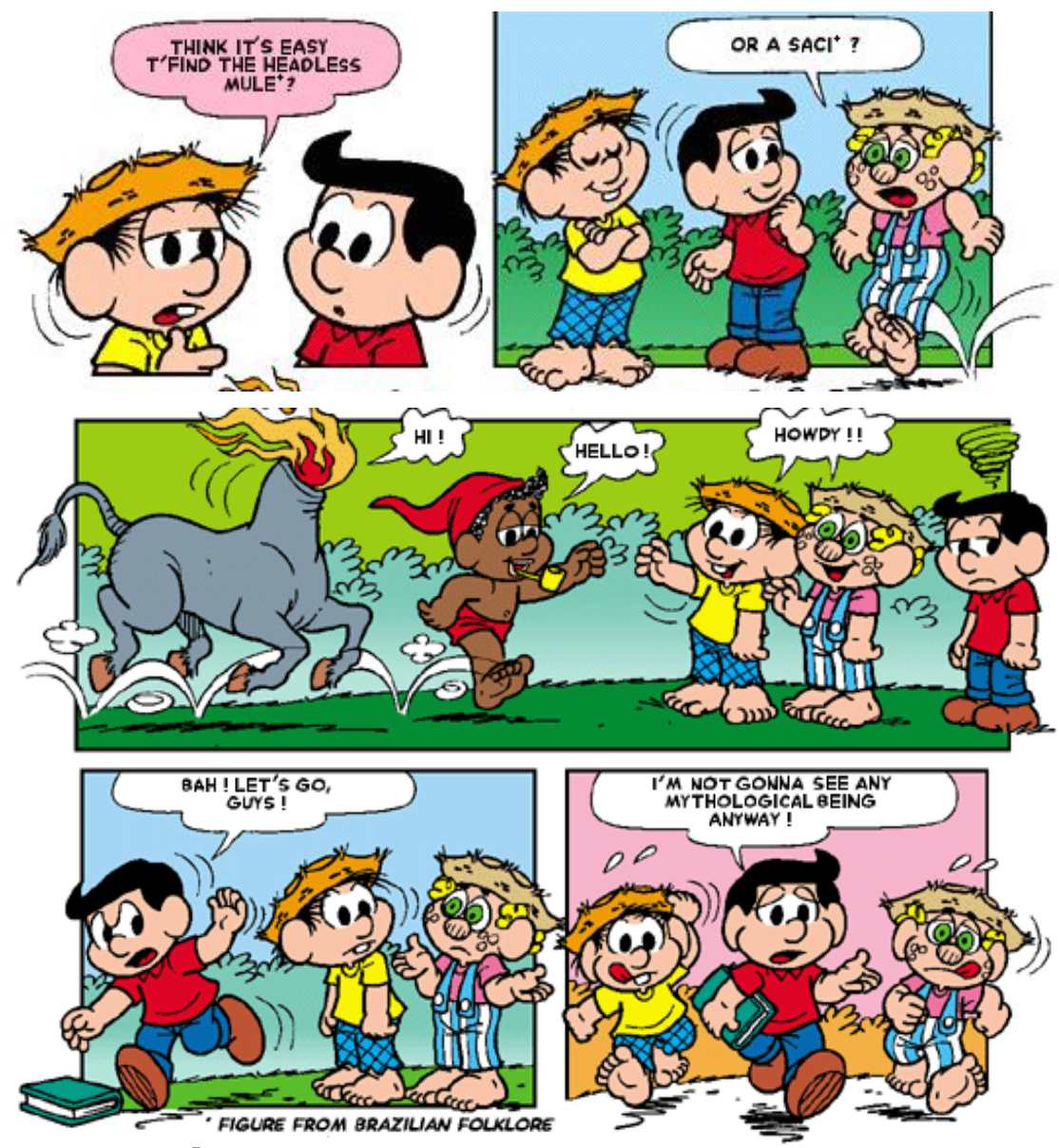

Copyright (C) 2001 Mauricio de Sousa Produçốes Ltda. Redistribution in whole or in part prohibited.

Figura 11:

Outro conflito similar ocorre no $2^{\circ}$ quadro da tira, porém, aqui não há uma relação entre o nome do personagem e as suas 
características na composição do termo 'saci', como no caso anterior. Há a necessidade do uso do empréstimo, uma modalidade de tradução de espelhamento, conjugada à explicitação, que apresenta o personagem folclórico ao público leitor que está em contato com a cultura estrangeira, como é possivel ver no asterisco que se segue ao termo 'saci' e sua referência no pé da página $\left(4^{\circ}\right.$ quadro).

Temos em seguida, duas ilustrações em que, para apoiar a tendência tradutória assimilativa do tradutor, permitiu-se uma alteração da imagem do quadrinho, eliminando, assim, os possíveis confrontos entre línguas e culturas:
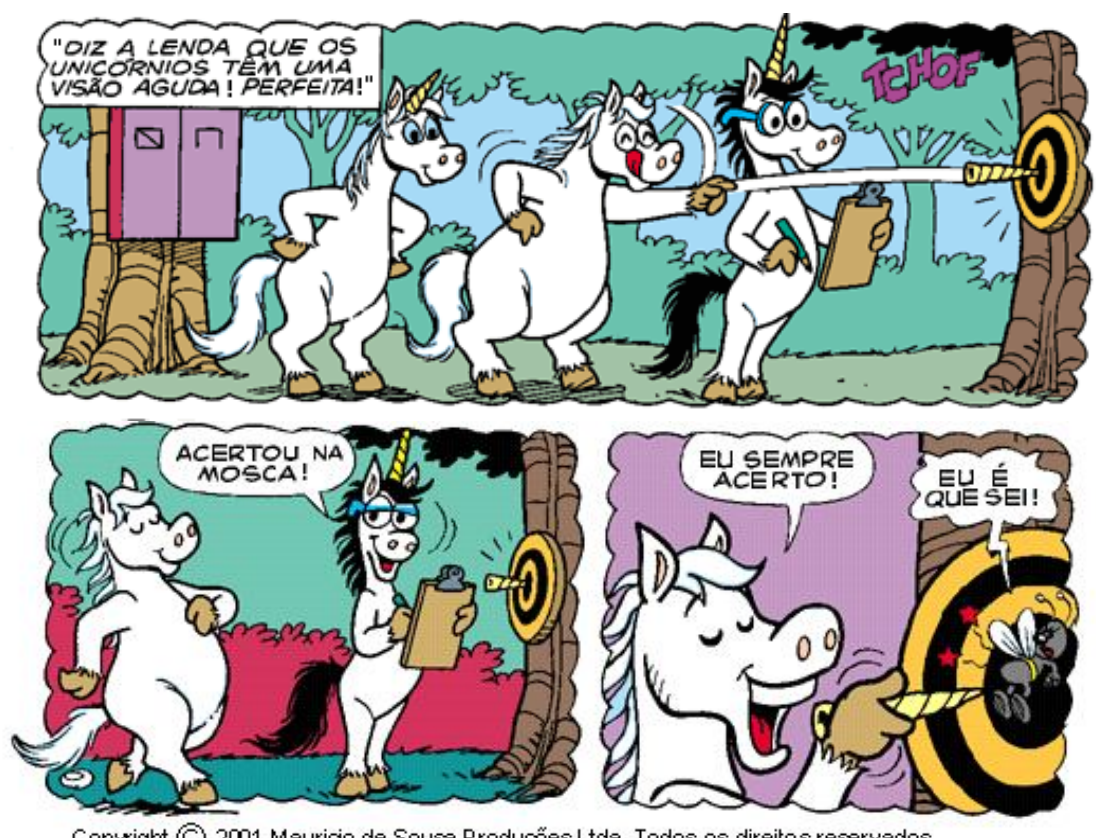

Copyright (C) 2001 Mauricio de Sousa Produộes Ltda. Todos os direitos reservados.

Figura 12: 

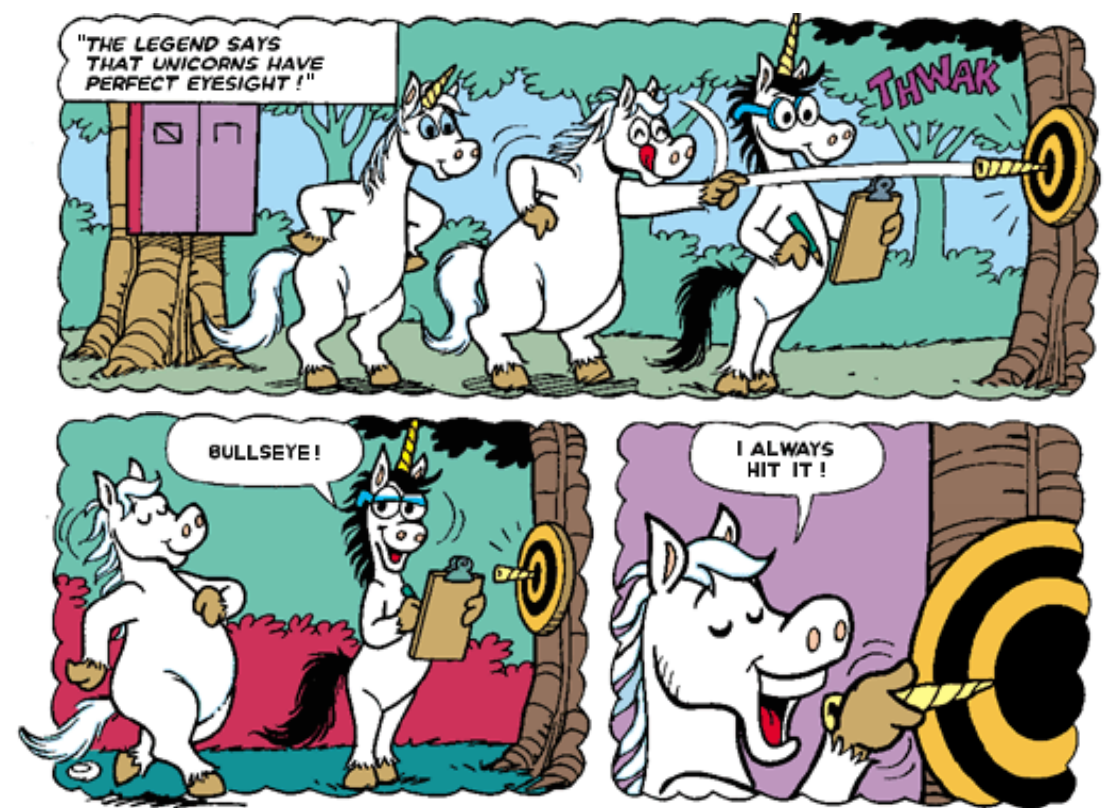

Copyright (C) 2001 Mauricio de Sousa Produộes Ltda. Redistribution in whole or in part prohibited.

Figura 13:

Essa sequência trata da fábula que o personagem, primo do Chico Bento, está contando para este. A expressão idiomática 'Na mosca!' ( $2^{\circ}$ quadro) tem o seu equivalente na língua inglesa: Bullseye!. No entanto, a piada que compõe essa sequência é exatamente a descrição ilustrativa da expressão "na mosca": o desenho de uma mosca brava, respondendo ao ataque sofrido no alvo. A escolha tradutória resultou um conflito imagético que foi solucionado pela alteração da imagem, a eliminação do desenho da mosca. Devido a essa alteração na imagem fez-se necessária, naturalmente, a exclusão total do balão da fala da mosca ("Eu é que sei!" - $3^{\circ}$ quadro).

No próximo exemplo, veremos um caso em que se tornou impossivel a não alteração da imagem, em auxílio do tradutor: 

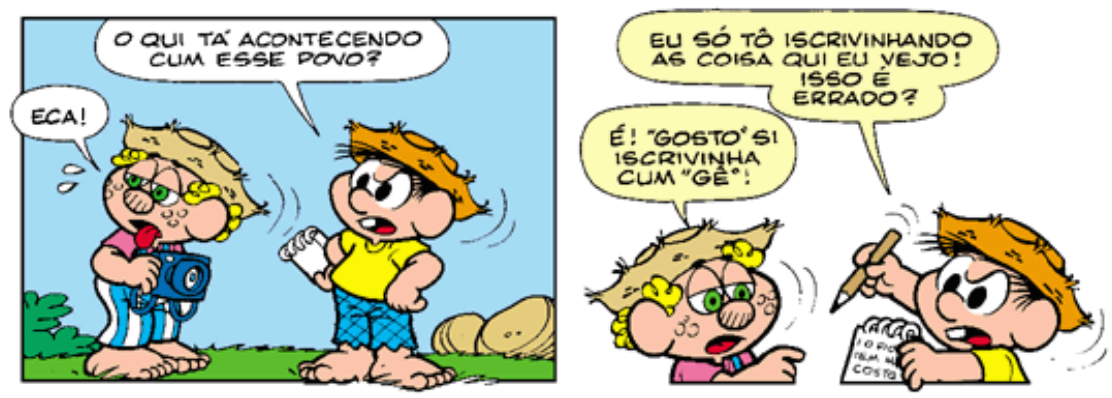

Figura 14:
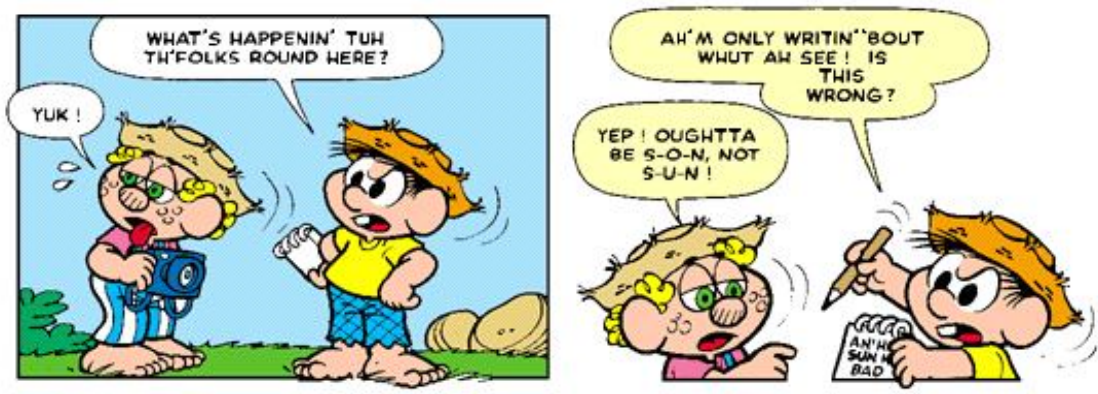

Figura 15:

Na Figura 14 ( $2^{\circ}$ quadro), destacamos a fala de Chico Bento "Isso é errado?" em relação à fala seguinte, do Zé Lelé, para a inclusão de uma piada que corresponde à ortografia. Vemos que, na tradução, há uma mudança imagética para acompanhar a escolha do tradutor, na qual o original apresenta "I o fio tem mal

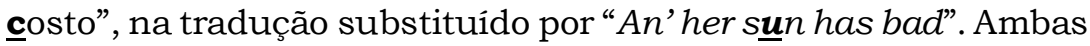
as frases compartilham do mesmo sentido; entretanto, possivelmente pelo fato de a palavra taste não caber no espaço da imagem, o tradutor optou por apontar o erro ortográfico em outro termo: son.

\section{Circunstâncias que orientam e precedem 0 trabalho do tradutor de HQs: as normas editoriais}

Vejamos, agora, algumas das condições identificadas na pesquisa que possivelmente cercaram o trabalho do tradutor

TradTerm, 16, 2010, p. 411-434 
nessa jornada quadrinhística no sentido de orientar, pelas normas editoriais, as escolhas tradutórias, inclusive no que diz respeito à relação imagem e texto.

No percurso da pesquisa, foi possivel obter um importante material formulado pela própria Maurício de Sousa Produções (MSP), que orienta e determina um padrão a ser seguido pelos tradutores que trabalham com os seus quadrinhos. Pelo contato direto com o departamento internacional da Mauricio de Sousa Produções, com sede em Nova York, obtivemos o Guideline $M S P^{9}$ constituído de uma série de normas a serem seguidas pelo tradutor no exercício de seu trabalho. Foram selecionados aqui os pontos que contribuem para a nossa pesquisa. São eles:

v Quando enviar as revistas para a tradução é muito importante que passe para o tradutor copia [sic] deste guideline e o modelo de tradução em file anexo.

$\checkmark$ A arte não pode ser modificada.

$\checkmark$ O número de palavras em cada frase deve ser adequado para caber no balão, que não poderá ser redesenhado ou conter letras de tamanhos diferentes.

$\checkmark$ Personalidades brasileiras desconhecidas no (país) que porventura aparecerem nas histórias deverão ser trocadas por personalidades internacionalmente conhecidas, mas sempre tendo o cuidado de mudar algumas letras, para não serem iguais aos nomes das celebridades.

$\checkmark$ Se os personagens nas histórias estiverem cantando alguma música conhecida somente no Brasil, trocar por musica popular do (pais)

$v$ Traduzir todas as onomatopeias.

9 Juntamente com o Guideline MSP, também recebemos a seguinte informação: "a máxima que norteia a MSP para a escolha e orientação dos nossos tradutores para outros idiomas: PRINCÍPIO DA TRADUÇÃO: 'O máximo da fidelidade à língua de partida, dentro do espirito da lingua de chegada'. Não basta dominar um idioma, é necessário saber do que se trata o texto. Conhecer detalhes do assunto, a terminologia daquele setor e a cultura de destino" (Departamento Internacional da Mauricio de Sousa Produções, grifos nossos)

TradTerm, 16, 2010, p. 411-434 
v O Chico Bento fala com grafia de caipira e se houver uma forma local para traduzir deverá ser usada.

As instruções acima indicam uma tentativa de padronização do trabalho do tradutor (em todas as línguas) para o qual, porventura, as histórias em quadrinhos, assim como quaisquer outros materiais da MSP, forem designados.

Como podemos ver, a orientação é taxativa em dois pontos principais: a manutenção da arte (desenho), tal como é reproduzida na cultura de partida; e a diretriz para adaptarem para a lingua meta os elementos culturais do original que sejam desconhecidos da mesma, tais como as personalidades da cultura pop e seu repertório musical.

$\mathrm{O}$ apagamento de figuras nacionais implica precisamente o apagamento da alteridade cultural presente no material que essa cultura divergente está em contato, pois parte de sua cultura, que poderia ser apresentada para este público, será substituída pelos mesmos referentes internacionalmente conhecidos da cultura hegemônica.

No entanto, como vimos anteriormente, algumas dessas orientações tiveram de ser flexibilizadas, exatamente pela amarração imagética que impossibilitou seu cumprimento. Em alguns casos, a regra de não alterar a imagem (ver Figuras 12 e 14) não pôde ser cumprida, do contrário a escolha tradutória não concordaria com o desenho. Outro caso interessante, que nos pareceu uma aquiescência no cumprimento das regras do Guideline, está no exemplo a seguir:
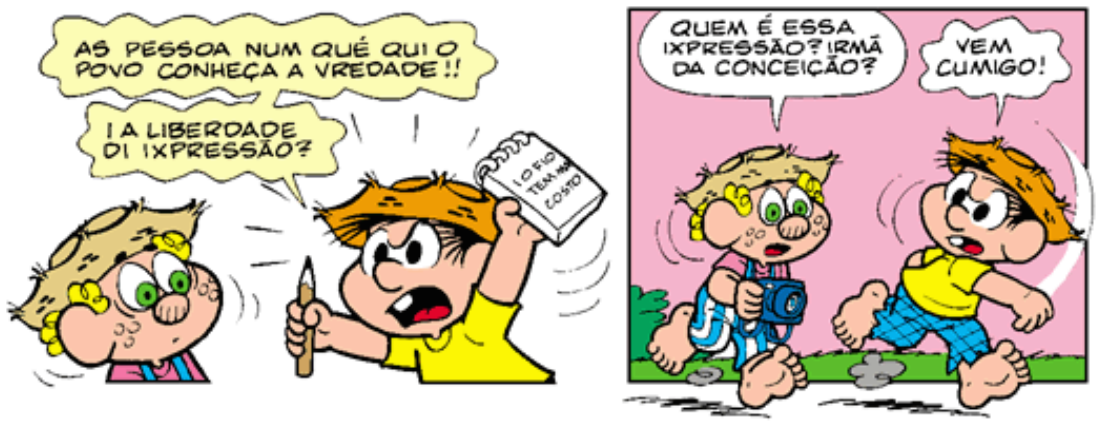

Figura 16:

TradTerm, 16, 2010, p. 411-434 

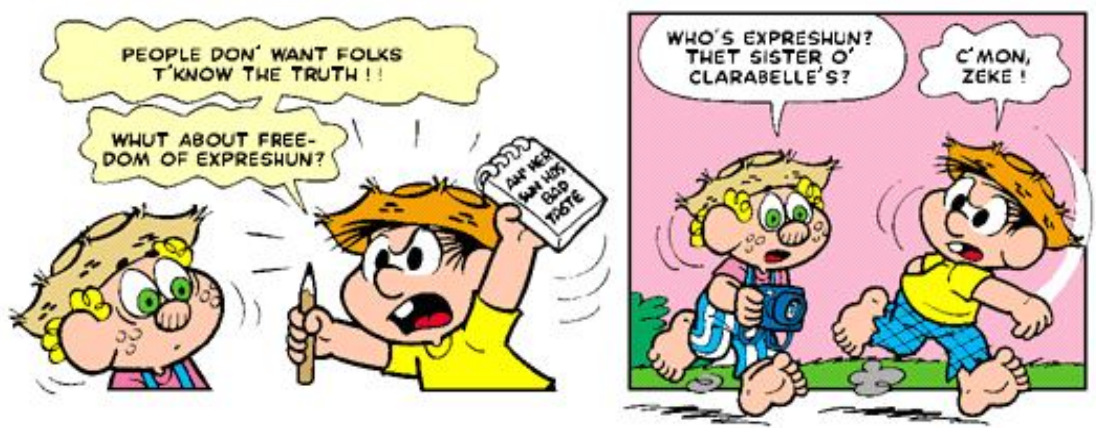

Figura 17:

A tradução do termo ixpressão/expreshun, nesse caso, sugere o desconhecimento do tradutor da mensagem do original. O personagem Zé Lelé pergunta "Quem é essa ixpressão? Irmã da Conceição?” (Figura $15-2^{\circ}$ quadro), e temos, na tradução, "Who's expreshun? Thet sister o'Clarabelle's?" (Figura 16 $2^{\circ}$ quadro). Acredito que a escolha do nome próprio Conceição (LF), no original, se deu pela necessidade de rimar com a palavra anterior: ixpressão (LF). No entanto, o tradutor não só ignorou a rima na sua escolha (expreshun - Clarabelt), como optou pelo nome de um personagem popular da cultura da LM, também dos quadrinhos, mas do universo Disney: Clarabela. Não temos certeza de que a modalidade de tradução seja exatamente erro, já que qualquer nome feminino bastaria para corresponder à piada do original, embora esta não rime com expression. No entanto, parece que o suposto "erro" possa ter sido motivado pela distração da rima no texto original, em paralelo à orientação do referido Guideline, em adaptar para a língua meta as "personalidades" em seu imaginário cultural.

Sobre as implicações que cercam o trabalho do tradutor, temos também o seu público-alvo. Sabemos que este é constituído de internautas, em sua maioria infanto-juvenil e estadunidense. As histórias em quadrinhos do Chico Bento que compõem o córpus selecionado são veiculadas na Internet ${ }^{10}$, chamado

10 http://www.turmadamonica.com.br/

TradTerm, 16, 2010, p. 411-434 
Portal da Turma da Mônica, que tem hospedagem no website da Globo.com, antiga editora das revistinhas ${ }^{11}$.

O chamado Gibi Virtual refere-se à recente tendência de unir a arte à tecnologia para acompanhar a velocidade com que a informação precisa chegar ao seu destino. A rede, nesse mundo globalizado, configura-se um espaço determinante de acesso à produção cultural entre distantes pontos ao redor do mundo, antes inimaginável; é, além disso, incrivelmente veloz.

Com os recursos da tecnologia, a divulgação em rede mundial de uma produção cultural popular (mass media), como as HQs, só acrescenta ao contato entre culturas, favorecendo a transmissão dos valores sociais, costumes e visão de mundo pertencentes a uma sociedade periférica, mas rica culturalmente.

O professor do núcleo de histórias e quadrinhos da Escola de Comunicação e Artes da USP, Waldomiro Vergueiro (2001:4), confirma que a veiculação da HQ na Internet é positiva: "a rede veio somar valores". Ele, aliás, não acredita que essa tendência possa reduzir o consumo de HQs em papel: "ainda não temos mecanismos que substituam o papel. As pessoas ainda estão muito ligadas ao manuseio do papel (...), não vão deixar a tecnologia acabar com um hobby", referindo-se aos colecionadores. E conclui: "o processo de leitura é completamente diferente, o que faz existir mercado para as HQs reais e virtuais".

O próprio Maurício de Sousa (1999:08), um dos pionei$\operatorname{ros}^{12}$ na veiculação de HQs na Internet, também discute essa nova prática positiva, afirmando que "são caminhos que não se cruzam. Muito pelo contrário, se somam"; além disso, garante que a rede mundial não é nada mais do que outro meio de estimular a leitura.

11 Todo o programa editorial da MSP passou a ser publicado, desde o dia 1 de janeiro de 2007, pela Editora Panini.

12 De acordo com Vergueiro (1999), o site da Turma da Mônica, veiculado na rede desde 1996, foi considerado diversas vezes o melhor site infantil brasileiro pela IBest. Cf. A odisséia dos quadrinhos infantis brasileiros: Parte 2: O predomínio de Maurício de Souza da Mônica. São Paulo: Agaquê, v. 2 n. 2 p. 8.

TradTerm, 16, 2010, p. 411-434 


\section{Considerações Finais}

Por essa razão, o nosso interesse justifica-se em não querer esgotar a discussão precisamente pelas consequências que o apagamento de uma cultura periférica (LF) pela hegemônica (LM) possa acarretar no contato entre-culturas. "Aplicada no espaço de recepção de uma cultura dominante, a tradução assimilativa torna-se domesticadora" (Aubert, 2003). Dessa forma, com as diferenças culturais anuladas pela tradução, a alteridade é desprezada, juntamente com toda a diversidade de valores e conhecimento que não serão compartilhados por aqueles que buscam esse contato.

No contexto do projeto de pesquisa, a hipótese formulada consistia em, com base nos resultados obtidos com o levantamento estatístico das modalidades de tradução (Aubert, 1998) no córpus inicial, mostrar a relevância da amarração imagética como elemento que limita a liberdade do tradutor por tratar-se de linguagem quadrinhística. Por exemplo, ao tentar desviar ou distanciar em grau máximo o texto meta do texto de origem utilizando a modalidade adaptação, supostamente para garantir a anulação do exótico presente no texto original - o tradutor depara-se com um entrave, pois sua escolha tradutória passa a depender do contexto visual no quadrinho.

Assim, a interdependência entre texto e imagem demonstrou ser um fator essencial no processo tradutório, exatamente por provocar limitações à tendência comum de assimilação à cultura de chegada, isto é, o relativo apagamento da marca cultural que caracteriza a alteridade do produto traduzido. No universo quadrinhístico, isso provou-se não mais se apresentar sem resistência.

\section{Referências bibliográficas}

AUBERT, F. H. (2006) Indagações acerca dos marcadores culturais na tradução. Revista de Estudos Orientais. São Paulo: DLO/FFLCH/ USP, n ${ }^{\circ}$, pp. 23-36.

(1998) Modalidades de tradução: teoria e resultados. TradTerm. São Paulo: Humanitas, $n^{\circ} 1$, pp. 99-128.

TradTerm, 16, 2010, p. 411-434 
CAGNIN, A. L. (1975) Os quadrinhos. S.Paulo: Ática.

CIRNE, M. (1972) Para ler os Quadrinhos. São Paulo: Ed. Vozes.

ECO, U. (2004) Leitura de "Steve Canyion" e O mundo de Minduim. Apocalipticos e Integrados. São Paulo: Perspectiva.

DISCINI, N. (2004) O estilo nos textos: história em quadrinhos, mídia, literatura. São Paulo: Contexto.

MOUNIN, G. (1975) Os problemas teóricos da tradução. São Paulo: Cultrix.

VENUTI, L. (1995) The translator's invisibility: a history of translation. London and New York: Routledge.

VERGUEIRO, W. (2001) Gibis virtuais. Diário Popular de S.Paulo, p. 4, 27 de março.

(1999) A odisséia dos quadrinhos infantis brasileiros: Parte 2: O predomínio de Maurício de Souza da Mônica. Agaquê. São Paulo, vol. $2 \mathrm{n}^{\circ} 2$.

TradTerm, 16, 2010, p. 411-434 